\title{
Possibilidades de uma rede intersetorial de atendimento a mulheres em situação de violência
}

\author{
Ligia Bittencourt Kiss ${ }^{1}$ \\ Lilia Blima Schraiber ${ }^{2}$ \\ Ana Flávia Pires Lucas d'Oliveira ${ }^{3}$
}

KISS, L.B.; SCHRAIBER, L.B.; D'OLIVEIRA, A.F.P.L. Possibilities of a cross-sector assistance network for women subjected to violence. Interface - Comunic., Saúde, Educ., v.11, n.23, p.485-501, set/dez 2007.

This article discusses data obtained from semi-structured interviews with 29 key informants from a set of services that provide assistance to women who are victims of domestic violence. It was investigated how these professionals perceive their work, what is the degree of interaction between them, and whether this does or does not characterize these services as a network, with a view to future integration with the primary healthcare services network. The authors conclude that diverse and conflicting operational rationalities coexist in this set but in such a way as to make it difficult to achieve actual integration. The inexistence of a common project reflects how difficult it is to articulate knowledge and care projects that have very different rationales, share no common interfaces and do not value each other. As it involves several sectors of assistance to the population of Brazil, integration depends on building communication channels and technological ways of providing assistance capable of enabling the adjustment of definitions and projects in order to meet shared objectives.

KEY WORDS: Violence against women. Gender. Networks. Intersectoriality. Women's health.

Discutem-se dados obtidos com base em entrevistas semi-estruturadas com 29 informantes-chave de um conjunto de serviços de assistência a casos de violência doméstica contra mulheres. Investigou-se como profissionais percebem seus trabalhos e qual o grau de integração das ações entre eles, a fim de caracterizá-los ou não como uma rede, com vistas à inserção dos serviços básicos da Saúde, ainda não participantes à época. Conclui-se que racionalidades operacionais diversas e conflitantes convivem nesse conjunto, constrangendo sua integração efetiva. A inexistência de um projeto comum reflete a dificuldade de composição entre saberes e programas de atenção com lógicas muito diversas, sem interfaces comuns e valorização mútua. Envolvendo diversos setores de assistência à população no país, a integração depende da construção de canais de comunicação e formas tecnológicas de assistência que permitam o ajuste de projetos e definições a objetivos compartilhados.

PALAVRAS-CHAVE: Violência contra a mulher. Gênero. Redes. Intersetorialidade. Saúde da mulher.

\footnotetext{
${ }^{1}$ Cientista social; antropóloga; doutoranda em Medicina Preventiva; pesquisadora, departamento de Medicina Preventiva, Faculdade de Medicina, Universidade de São Paulo. São Paulo, SP. <ligiakiss@usp.br>

${ }^{2}$ Médica; livre-docente em Medicina Preventiva; professora, departamento de Medicina Preventiva, Faculdade de Medicina, Universidade de São Paulo. São Paulo, SP. <liliabli@usp.br>

${ }^{3}$ Médica sanitarista; doutora em Medicina Preventiva; professora, departamento de Medicina Preventiva, Faculdade de Medicina, Universidade de São Paulo. São Paulo, SP. <afolive@usp.br>
} 


\section{Introdução}

Mediante o mapeamento dos serviços que prestam assistência a mulheres em situação de violência, este estudo investigou a existência de uma possível rede intersetorial. $\mathrm{Na}$ investigação, foi privilegiada a violência por parceiro íntimo e por familiares em detrimento daquela perpetrada por outros (conhecidos e estranhos), por serem as primeiras as principais $e$ predominantes situações de violência contra a mulher (VCM), no Brasil e no mundo (Garcia-Moreno et al., 2005). Buscou-se compreender como os diversos serviços e seus atores percebem seu lugar no conjunto da assistência, relacionam-se e integram-se, em sua definição do problema $e$ propostas de intervenção. As considerações aqui desenvolvidas tomam por base empírica um levantamento de serviços tal como se apresentavam no primeiro trimestre de 2000, a fim de se elaborar um guia atualizado do conjunto deles para o município de São Paulo (Guia de Serviços, 2000). Os resultados da investigação também serviram de base para subsidiar a implantação de atendimentos à VCM na área da saúde, especialmente na rede pública de atenção primária em São Paulo. O estudo foi financiado pela Fundação Ford e teve seu desenho aprovado pelo Comitê de Ética em Pesquisa da Faculdade de Medicina da USP (CAPPesq).

O primeiro passo da investigação foi identificar quais serviços já atuavam no município de São Paulo e quais suas vocações assistenciais, no sentido de reconhecer a principal modalidade assistencial de cada serviço. Destes, excluíram-se os hospitais especializados, ligados à violência sexual por estranhos e ao aborto legal, em razão da mencionada ênfase na violência de caráter doméstico. Com isso, diminuiu-se muito a presença do setor saúde no conjunto dos serviços aqui analisados, até porque, no início do ano de 2000, a presença de centros de saúde nesse tipo de atendimento era fortuita, ainda que a atualização dessas informações, realizada em 2005, demonstre o grande crescimento da participação do setor saúde no conjunto de serviços voltados para a VCM (D'Oliveira et al., 2005).

Para os serviços estudados, com base em depoimentos de seus profissionais, buscou-se reconhecer qual o grau de integração das ações, a fim de caracterizá-los ou não como uma rede, pensada como interconexão $e$ interdependência de fluxos dos diferentes trabalhos. Além da integração das ações, investigaram-se as interações dos sujeitos e subgrupos que compõem o conjunto desses serviços (Peduzzi, 1998). O objetivo foi explorar as possibilidades de interlocução e comunicação interinstitucional, caracterizando-os como rede na dimensão interativa.

Consideramos, pois, rede intersetorial a articulação objetiva das ações interinstitucionais e a interação entre seus agentes, além da presença de canais definidos de comunicação entre os serviços que compõem nosso conjunto e, potencialmente, participariam de uma rede.

Concordamos com Emirbayer \& Goodwin (1994), para quem rede intersetorial é considerada como estrutura em que convivem atores e suas relações, com seus ideais, quadros discursivos e mapas cognitivos, e de cuja constituição participam ideologias políticas e discursos culturais, que, nas suas convergências e divergências, podem afastar ou aproximar os sujeitos 
que a integram. Nesse sentido, as afinidades entre as atitudes dos sujeitos que representam as instituições e organizações e sua trajetória biográfica teriam um peso considerável nas possibilidades de conexões e na qualidade dessas conexões, que também se fazem presentes na consolidação ou não da rede em torno de metas e objetivos comuns.

Com base na própria história de constituição desses serviços, nossa hipótese é a de que, criados como setores independentes de assistência, ou atendendo a situações de VCM dentro de um programa mais geral de atendimento a questões da família ou da mulher, dificilmente a noção de rede será aplicável ao conjunto desses serviços. No entanto, é possível que aspectos parciais, na articulação das ações ou na interação de seus agentes, ou ainda da comunicação das instituições, sejam encontrados. Não obstante, as opiniões e críticas dos entrevistados certamente contribuirão para um reconhecimento dos principais obstáculos à constituição da rede, bem como das principais possibilidades existentes nessa direção.

\section{Um breve histórico da constituição de um conjunto intersetorial de serviços atinentes à VCM}

A partir da década de 1980, no Brasil, a VCM transformou-se em um dos grandes eixos de ação do movimento feminista no sentido assistencial, dando início à realização de parcerias com o Estado destinadas à formulação de políticas públicas que contemplassem a questão de gênero (Farah, 2004). Na área da assistência jurídica, em 1984, o Conselho Estadual da Condição Feminina em São Paulo impulsionou a criação dos Centros de Orientação Jurídica e Encaminhamento (COJE), com base em um serviço voluntário de orientação e encaminhamento legal para mulheres em situação de violência (Barsted, 1994). Estimulada por essa experiência, numa ação internacionalmente pioneira, foi também instituída, em 1985, a primeira Delegacia Especial de Atendimento a Mulheres (DEAM), também chamada, em alguns lugares, Delegacia de Defesa da Mulher (DDM).

Dentro de uma vocação diferente daquela verificada nas instituições jurídico-policiais e um pouco anteriormente à instituição da primeira DDM, no início da década de 1980, foram criados os SOS-Mulher. A proposta desses serviços, no momento de sua criação, já era vista como uma nova estratégia do movimento organizado de mulheres, que buscava oferecer informações acerca da assistência judicial e outras modalidades de suporte, considerando a forma desrespeitosa com que mulheres eram tratadas nas delegacias comuns de polícia.

Foi, também, a partir da década de 1980, que a articulação entre ONGs e grupos organizados de mulheres possibilitou a criação de novos canais de comunicação e formas de diálogo entre movimentos sociais e Estado. Os centros de referência, como a casa Eliane de Grammont, em São Paulo, que oferecem assistência jurídica, social e psicológica, são um expoente desse processo. Essas instituições foram concebidas como locais de recuperação da capacidade de inserção social e auto-estima da mulher (Farah, 2004).

Apesar do inquestionável avanço representado pela inserção da questão no escopo das políticas públicas, tal solução não se apresentou como 
definitiva na resolução do problema, nem representou, ainda, um compromisso oficial do Estado com a comunidade internacional no combate efetivo da VCM. Segundo Saffiotti (2002), a criação da primeira Delegacia da Mulher estava "...destinada a ser uma medida isolada, não uma política pública de combate à violência doméstica. Posteriormente, dezenas de DDMs foram criadas sem que se qualificassem seus profissionais (muitas mulheres e alguns homens) no tema relações de gênero" (p.61). Carrara (2002) aponta a tendência de promotores e juízes de considerarem cada caso como um evento isolado: "Para eles, de um modo geral, não parece existir uma 'violência contra a mulher', mas violências específicas contra mulheres singulares" ( $p .80$ ).

A eficácia das Delegacias de Mulher no combate à VCM é, ainda, colocada em dúvida por outra pesquisa. Massuno (2002) diz que, mesmo se a quantidade de denúncias revela-se superior a cada ano, parece haver um descompasso entre a demanda dessas mulheres e as soluções propostas pelas delegacias, o que se evidencia no grande número de queixas que são retiradas. Além disso, o caráter agressivo e punitivo da polícia brasileira também se revela, muitas vezes, como uma violência a mais na vida das mulheres.

Há, também, uma outra ordem de problemas. Enquanto, na delegacia, os casos de violência são abordados do ponto de vista legal, sendo criminalizados de acordo com as disposições da lei federal a respeito do assunto (D'Oliveira, 2000), a compreensão das mulheres em relação ao problema geralmente envolve dimensões subjetivas que divergem bastante em forma e conteúdo das definições jurídico-policiais (Campos, 2002; Brandão, 1998). Carrara (2002), por sua vez, questiona a tese comumente aceita da ineficiência das delegacias e de seus profissionais. Em pesquisa realizada no Rio de Janeiro, o autor afirma:

\footnotetext{
A observação sistemática do trabalho realizado pelas Delegacias Especiais de Atendimento a Mulheres tem permitido aos pesquisadores percebê-las enquanto instâncias privilegiadas para negociação de conflitos. O número reduzido de queixas que se transforma em inquéritos enviados à justiça expressaria, portanto, não apenas a morosidade ou a ineficiência da polícia, mas a ocorrência de uma experiência singular de mediação de conflitos, de arbitragem extra-oficial, onde, graças à autoridade de delegadas e detetives, as correlações de forças e os valores já cristalizados no seio da família podem ser alterados. Os dados etnográficos coletados por estes pesquisadores revelaram ainda que, em muitos casos, as DEAMs produzem uma espécie de pedagogia prática, por meio da qual altera-se o próprio padrão de percepção da violência exercida sobre mulheres que, às vezes, submetidas a muitos anos de abusos sexuais e agressões, incorporam e naturalizam tais atos, não os identificando como violentos e, muito menos, como criminosos. (Carrara, 2002, p.72)
}

Assim como no caso das DEAM, há também controvérsias quanto à eficiência atual dos COJE, desvinculados do projeto original que incentivou sua criação. No âmbito das políticas públicas, os COJE foram afastados das iniciativas 
originais do movimento de mulheres que deram forma à sua institucionalização a partir da sua desvinculação do Conselho Estadual da Condição Feminina e realocação na estrutura da Procuradoria Geral do Estado, o que se deu em 1986. De acordo com Barsted (1994, p.47), "tal fato contribuiu para esvaziá-lo do fundamento ideológico feminista, que antes marcara sua atuação". Distantes do contexto de sua criação, não haveria mais a identificação original com as propostas do movimento.

A saúde e os direitos reprodutivos são inseridos na agenda feminista a partir da década de 1980, expressos como demandas em políticas sociais (Pinto, 1999). Mas é a partir de 1990 que o movimento de mulheres remete, estrategicamente, a discussão da violência aos campos da saúde e do desenvolvimento social. O tema incorpora, então, novas linguagens e passa a ser explorado como um problema de saúde, vinculado ao campo das políticas públicas (Schraiber \& D’Oliveira, 1999).

A princípio, pode-se considerar que a abordagem da saúde contrastaria com a jurídico-policial, em primeiro lugar, pelo sentido das intervenções propostas: enquanto a primeira concentra-se na "vítima", dentro de uma perspectiva propositiva, na segunda, o alvo é o agressor, dentro de um modelo reativo (Weisberg apud Minayo \& Souza, 1997-98). No entanto, em ambos os casos, permanecem desajustes quanto às linguagens utilizadas, de um lado, pela mulher que vivencia a situação e, do outro, pelo profissional a quem recorre. Conforme D'Oliveira (2000, p.9):

\footnotetext{
Se não é exatamente uma demanda pela ação penal diante de um possível crime para os policiais, o sofrimento da mulher em situação de violência tampouco é doença para os médicos e profissionais de enfermagem, a não ser que haja alguma base anatomopatológica objetiva para justificá-lo.
}

\section{Desenho do estudo e metodologia}

O primeiro passo do estudo foi identificar os serviços que constituiriam o conjunto de atendimentos a mulheres em situação de violência a ser investigado, levantando-se listagens desses serviços. Foram localizadas 46 diferentes unidades assistenciais (Guia de Serviços do Município de São Paulo, 1999), duas das quais atuando em mais de uma modalidade de atendimento, totalizando a prestação de 48 tipos de serviços oferecidos nas 46 unidades assistenciais: 11 do tipo assistência policial, 14 do tipo assistência e/ ou orientação jurídica, 17 do tipo assistência psicossocial (dez especializados e sete básicos) e seis de atenção à saúde, dos quais quatro hospitalares. Dentre eles, há serviços públicos e ONGs.

A seguir, excluídos os hospitais, o conjunto restante, de 44 serviços, foi classificado em quatro vocações assistenciais: Policial, Jurídica, Psicossocial Especializada e Orientações Básicas. Esta última vocação agrupou ações que podem atuar em saúde e em orientação psicossocial básica. De cada um dos 44 serviços, buscou-se entrevistar um informante-chave.

A metodologia utilizada consistiu na análise de discursos coletados em entrevistas semi-estruturadas, gravadas e transcritas.

Neste estudo, os discursos produzidos pelos diversos profissionais foram 
considerados como reflexão e depoimento acerca do trabalho que realizam, instigados pelas questões do roteiro da entrevista. Isto significa que, ao mesmo tempo em que descrevem seu processo de trabalho e explicitam de quais saberes se valem nesse trabalho, emitem opiniões e juízos de valor acerca do realizado (Schraiber, 1995). Segundo a autora, visto como ação social, o trabalho possui uma intenção técnica, ética e política em ato. Isso significa que os sujeitos que o realizam possuem olhares e linguagens peculiares segundo o contexto de sua prática e suas posições individuais. Além de produtores e reprodutores da técnica específica que atualizam em seu trabalho, os sujeitos são informados por crenças, valores e atitudes que não se restringem ao universo concreto da sua prática cotidiana de trabalho. Ao mesmo tempo em que é técnica e saber atualizado, o trabalho incorpora as relações intersubjetivas envolvidas nele. Assim, trabalho é técnica e ação instrumental, mas é, também, interação e linguagem. São esses elementos que se articulam na produção da assistência.

Os diferentes profissionais entrevistados foram estimulados a realizar uma reflexão sobre suas práticas, além de terem sido instigados, na entrevista, a realizar a mesma reflexão acerca das práticas dos agentes de outros serviços que potencialmente participariam da rede.

\section{Resultados}

Os resultados foram apresentados por vocação de assistência, de forma comparativa $e$, na conclusão do texto, essas comparações são sintetizadas, discutindo-se possibilidades e limites para a integração da rede especializada de atendimento a mulheres em situação de violência. Relembramos que todos os dados aqui considerados são relatos dos entrevistados, incluindo-se aqueles que caracterizam mais objetivamente os serviços. Dos 44 serviços procurados, concederam entrevistas oito delegadas da Assistência Policial, sendo sete de DDMs e uma da Delegacia Policial de Proteção ao Idoso; oito profissionais de serviços de Assistência e Orientação Jurídicas; seis de Assistência Psicossocial Especializada; e sete de Centros de Orientações Básicas. Totalizam, assim, 29 depoimentos, com uma perda de 34,1\% em relação ao total de serviços contactados. A recusa foi justificada como dificuldade de agendamento, e não como resistência frente ao tema.

\section{Assistência policial}

As delegadas vêem-se inseridas em uma estrutura corporativa, com normas $e$ diretrizes bastante homogêneas na sua aplicação. Enxergam, porém, o papel da Delegacia da Mulher (DDM) e sua função na corporação como desvalorizados pelas demais instâncias policiais. Consideram que a DDM sempre foi vista pela polícia como desprestigiada, da mesma forma como os delitos relativos ao âmbito doméstico são social e historicamente considerados menos importantes que aqueles da esfera pública. As próprias entrevistadas não necessariamente valorizam a existência da instituição e sua proposta: 


\begin{abstract}
A DDM é discriminatória. Por que um atendimento diferenciado para as minorias? Sensibilidade não depende de homem ou mulher, mas num plantão comum, há outras prioridades. A DDM foi pensada como transitória, mas parece que acabou sendo definitiva.
\end{abstract}

As DDM possuem um cotidiano de trabalho "protocolar", marcado pela seqüência repetitiva e pouco flexível de atendimento. As decisões são centralizadas na figura das delegadas e não envolvem discussões em equipe. Sua função é classificar o relato $e$ as queixas em uma ou mais figuras de lei $e$ dar seqüência aos procedimentos jurídicos cabíveis em cada caso.

A escuta é um procedimento valorizado estritamente pela sua função: recolher as informações necessárias à continuidade do trabalho. $\mathrm{O}$ atendimento é pensado exclusivamente com base na necessidade de iniciar o caso na trajetória legal, traduzindo-o nos termos da lei. Informações tidas como desnecessárias a este procedimento são dispensadas. Agindo dessa forma, as delegadas circunscrevem seu objeto de trabalho, impondo limites à interação com as usuárias e com outros atores da rede.

Vou direto ao assunto. Não tenho tempo para ficar ouvindo. A mulher chega querendo contar toda a vida dela... Muitas vezes, o tempo do crime até já prescreveu.

Aqui é Delegacia de Polícia. Fizemos curso de capacitação para delegacia da Mulher, mas não tenho formação de psicólogo ou assistente social. A função é policial.

Possuem uma definição do problema e das intervenções pertinentes bastante diversa da dos demais atores e, por isso, são alvos constantes de críticas. Apesar disso, constituem-se na principal e mais tradicional referência entre os serviços. As DDM são as instituições mais mencionadas como receptoras de encaminhamentos das demais, mesmo porque são as únicas que possuem instrumentos para atingir diretamente o agressor. Além disso, conforme já mencionado, são historicamente as primeiras instituições em políticas públicas voltadas para o atendimento de mulheres em situação de violência.

Utilizam a linguagem da lei $e$ do crime e esperam da mulher o reconhecimento do seu problema nestes termos. Parecem frustradas com o uso da delegacia feito por mulheres que tomam o processo como uma maneira de negociar o relacionamento com o parceiro agressor, considerando este um uso indevido da delegacia. Para elas, as mulheres parecem esperar mediação de seu conflito na esfera privada, enquanto as delegadas desejam uma trajetória sem retrocessos, típica dos litígios da esfera pública. Antecipam, como produto do seu trabalho, a condenação do agressor e, quando uma decisão da mulher interrompe o processo, sua queixa perde legitimidade do ponto de vista das profissionais.

As mulheres recuam antes do final do processo. Só querem colocar o marido para fora de casa, ameaçar... Acabam não seguindo o inquérito. Não querem se separar, só dar um susto. 
As mulheres fazem a queixa, retiram a queixa e voltam com a mesma queixa.

Percebem que a delegacia, muitas vezes, funciona como uma instância de mediação de conflitos privados, conforme apontou Carrara (2002), porém as delegadas não reconhecem uma dimensão pedagógica no seu trabalho. Acreditam que as mulheres possuem um padrão de comportamento não influenciável ou alterável pelas ações desenvolvidas na DDM.

As mulheres que voltam sempre, não estão a fim de mudar.

Acontece [a VCM] se a mulher permite. A mulher não deve permitir desde a primeira. Se a pessoa der margem, o fato vai ocorrer sempre.

Das oito entrevistadas, apenas uma considera a delegacia também como um local de abertura para a fala da mulher, mas o que a mulher diz não é tomado como parte do processo de trabalho. É algo que é pensado e se faz pela mulher com uma conotação solidária, de caráter pessoal. O relato considerado importante é o dos fatos concretos. Os demais componentes da narrativa da mulher, que não se encaixam nos artigos previstos na lei, não participam da solução antevista para o caso, nem como objeto de encaminhamentos.

Aquilo que não se encontra nas definições e prescrições legais é interpretado com base em crenças advindas do senso comum e valores individuais. Muitas vezes, as mulheres em situação de violência ficam expostas a julgamentos de ordem moral pelas trabalhadoras do serviço.

\footnotetext{
As mulheres conhecem parceiro, nem sabem o nome e já estão morando no mesmo barraco.

Mulher é o sexo frágil. O homem não arruma briga com quem pode enfrentá-lo.

Os nordestinos são como senhores feudais, pensam que são donos das suas filhas.
}

As delegadas não lidam com o tema de forma mais global e integrada a questões de gênero, de saúde e de sofrimentos psicológicos. Naturalizam a posição sociocultural de homens e mulheres e, quando o caso não cabe na sua definição dos trâmites legais, apelam para justificativas que condenam a forma, ora das mulheres, ora dos homens, de atuarem e se posicionarem no mundo.

Mulher acha que pode conseguir mudar o marido.

A cama resolve tudo.

Solução é difícil enquanto o homem for homem. 
A maioria das delegadas entrevistadas acredita ser o crime de violência sexual por estranhos mais grave e prioritário no atendimento. Além da maior legitimidade histórico-social do reconhecimento do abuso sexual por estranhos como crime, parece mais fácil, nestes casos, identificar a mulher como vítima.

A maioria da demanda que recebem é por procura espontânea do serviço. De maneira geral, conhecem muito pouco os outros serviços da rede, e as principais referências que têm, afora o Judiciário, estão relacionadas ao atendimento hospitalar de casos de aborto legal.

Em comum com as demais esferas de atendimento, as delegadas percebem um descompasso entre a demanda da usuária $e$ a oferta do serviço. As mulheres esperam a resolução rápida de suas queixas, porém são obrigadas a se submeter à demora dos procedimentos jurídicos e policiais.

As mulheres não entendem o funcionamento da delegacia, esperam a transformação do companheiro.

A maioria das mulheres mistura o que é serviço de delegacia e de advogado. Querem que você tire o marido de casa. A delegacia não tem atribuição para isso.

Não há consenso entre as delegadas quanto à importância do atendimento psicossocial. Enquanto algumas acreditam que este tipo de atendimento não é resolutivo, outras reconhecem a necessidade de um acompanhamento multiprofissional, em que destacam o papel de psicólogos e médicos, nesta ordem.

Entre as causas atribuídas à VCM, as questões de negociação do casal ganham destaque. Nesse sentido, o machismo, a ausência de diálogo e ciúmes são vistos como principais causas da violência, ainda que, como referido anteriormente, não integrados em uma visão de gênero. A causa mais imediata das situações de violência, na opinião das delegadas, é o abuso de álcool pelo parceiro.

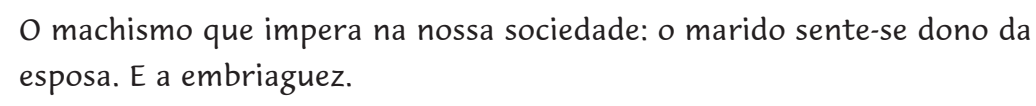

A agressividade do ser humano não foi tratada. Como se trata? É possível tratar?

Não acha briga no bar, vai bater na mulher.

\section{Assistência jurídica}

A maioria dos serviços de assistência e orientação jurídicas tem, entre seus objetivos, o atendimento à população de baixo poder aquisitivo e exige comprovação de renda. Há uma triagem inicial que busca verificar as condições de renda do usuário com o objetivo de decidir incluí-lo ou não no atendimento. 
Por não se dedicarem, em sua maioria, exclusivamente ao atendimento de VCM, os profissionais desses serviços possuem discursos bastante diversos sobre o tema, não demonstrando grande potencial de inclusão e integração em uma potencial rede de assistência a mulheres em situação de violência.

Com exceção de um dos entrevistados, todos os demais possuem formação universitária, completa ou não, na área de Direito. A rotina de atendimento é bastante padronizada, organizada em fluxos que correspondem às trajetórias e possibilidades jurídicas dos casos.

Provavelmente, devido à situação socioeconômica dos usuários que os serviços se propõem a atender, transparece, nos discursos, uma visão de sociedade na qual prevalecem questões relacionadas à desigualdade social. A VCM é também interpretada dessa perspectiva, na qual a pobreza se constitui em um aspecto central das atitudes das pessoas em relação à vida. Nesse sentido, alguns entrevistados pensam o contexto socioeconômico como condicionante de um padrão de relações entre homens e mulheres, em que se vêem reproduzidas as iniqüidades. Há uma série de estereótipos nesses discursos, que atribuem lugares fixos e imutáveis aos parceiros dentro dos relacionamentos em que se envolvem. O uso de álcool e drogas pelo homem aparece, também, como uma das principais causas mencionadas da VCM, sendo colocado como diretamente responsável pelas agressões perpetradas.

\footnotetext{
Há uma cultura machista de que ele tem que sustentar a casa. Esta entende-se de tal modo que, quando ele não consegue suprir as necessidades da casa, parte para a bebida e desta para a agressão. No meio tempo, ela evita ter relações com ele porque não agüenta: ele não toma banho.
}

Se as condições de vida melhorassem, somente restariam aqueles casos de problemas psicológicos e psiquiátricos.

Nas classes mais altas, a mulher se sujeita menos.

Da situação socioeconômica da clientela dos serviços decorreria, também, a falta de acesso à informação, a incompreensão quanto ao andamento do processo e as dificuldades de comunicação entre prestadores e usuários.
A gente tem dificuldade em entender o que o usuário quer e explicar o que pode ser feito, isso porque a maioria dos clientes é muito carente.
Muitas pessoas não compreendem o andamento do processo.

Os usuários são carentes de direitos, de conhecimentos, de atenção.

Também são muito simples, têm dificuldade até para se comunicar.

De forma geral, os profissionais da Assistência e Orientações Jurídicas desconhecem outros serviços que atendem mulheres em situação de violência, possuindo pouca ou nenhuma perspectiva de trabalho 
intersetorial. Recebem e mandam encaminhamentos quase exclusivamente para outras instituições voltadas ao atendimento jurídico ou policial.

Estamos limitados na parte jurídica.

\section{Assistência psicossocial}

Os discursos coletados entre as profissionais da assistência psicossocial diferiram bastante em relação ao das delegadas e das profissionais da assistência jurídica. As entrevistadas pensam sua inserção na rede como parte de um projeto pessoal, nascido em trajetórias de vida marcadas pelo engajamento no movimento feminista e em propostas de mudança social. Sentem-se compromissadas com seu trabalho, mas apontam a dificuldade que enfrentam em ter reconhecimento por outros profissionais, seja da área médica ou da policial.

As profissionais da assistência psicossocial são, em sua maioria, psicólogas. Dominação, impulso, desejo, auto-afirmação, insegurança, psiquismo, complexo de Édipo e castração são alguns dos termos usados para qualificar os móveis da VCM, que é vista como relacional pela maioria das entrevistadas. No entanto, a importância conferida à esfera da subjetividade e emoções não implica a ausência de temas sociais nos discursos produzidos. Nesse sentido, a precariedade da situação financeira das famílias de baixa renda e a insuficiência de políticas públicas são apontadas como componentes de um contexto onde a violência estaria propícia a ocorrer. Assim como na assistência jurídica, a temática de classes sociais permeia o trabalho desenvolvido nesses serviços desde o momento da entrada das mulheres nesse atendimento. Possuem, também, uma triagem que obedece a critérios de renda, sendo excluídas as pessoas com renda superior a um montante preestabelecido.

Por se tratar de serviço público, para a população carente, a violência acaba se cruzando com a questão da miséria.

As entrevistadas dos serviços de assistência psicossocial são aquelas com maior comprometimento em relação ao discurso de gênero, definindo a VCM com base na desigualdade das relações entre homens e mulheres. Pensam no problema como uma questão do âmbito cultural. A idéia do projeto de vida feminino como informado pelo ideal do casamento e família pesa bastante na descrição que elaboram dos valores e atitudes das mulheres a que atendem e o tipo de expectativa apresentado por elas. De acordo com essa perspectiva, a assistência é pensada como um esforço no sentido de promover a emancipação da mulher, seu fortalecimento e independência.

Uma das diferenças apontadas em relação às delegacias refere-se ao tipo de escuta oferecido pelos serviços. Enquanto, na delegacia, a escuta centra-se no registro da queixa, na assistência psicossocial, a fala da mulher é o núcleo do trabalho. Transformar essa fala em objeto de reflexão e crítica pelo sujeito do atendimento, para posterior reconstrução e/ou ajustes no projeto de vida da mulher, é a finalidade do trabalho realizado. A narrativa das 
usuárias participa ativamente da construção do produto de trabalho, posto que, valendo-se dela, as profissionais têm acesso ao objeto de seu trabalho, isto é, a situação de violência.

Há uma grande dificuldade de comunicação entre os serviços da assistência psicossocial e policial. Apesar de as DDM participarem ativamente da rede de encaminhamentos, como destinatárias e enviantes, destoam no sentido da definição do problema e, sobretudo, da proposta de atendimento. Há forte crítica dos profissionais da assistência psicossocial quanto à prática assistencial desenvolvida nas delegacias, sendo a principal a falta de disposição das profissionais para a escuta e acolhimento. Esperam das delegadas uma maior sensibilidade no tipo de acolhimento que prestam, e a valorização das queixas e do contexto de vida das mulheres.

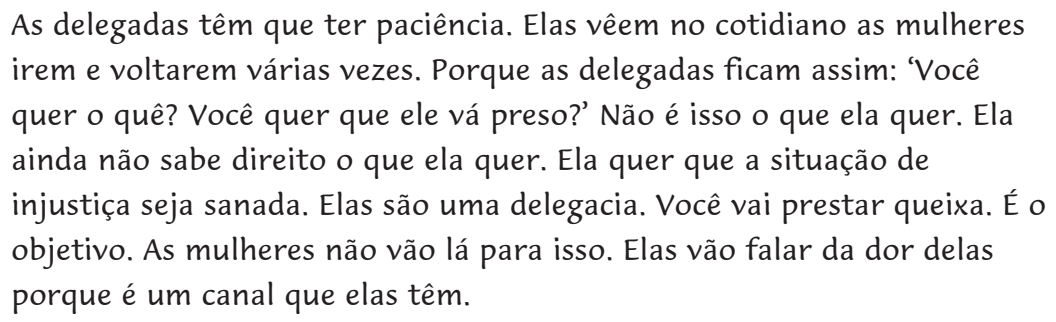

Entendem a resolução dos casos de VCM mais como um processo do que apenas como uma decisão que leva a uma ruptura.

Diferenciam os objetivos do atendimento jurídico e psicossocial, mas apontam a dificuldade de compreensão entre os trabalhos dos diferentes serviços e setores da assistência. Apesar de reconhecerem a necessidade da integração dos serviços e afirmarem a necessidade de encaminhamentos, parcializam e segmentam a assistência por não confiarem no projeto de intervenção dos outros serviços.

\footnotetext{
A questão da veracidade dos fatos é uma questão judicial. A gente vai trabalhar aqui com a qualidade psíquica, tentar entender o psiquismo dessa família, mas não com intuito de ajudar no processo, colocar na cadeia, por exemplo. Mas eles [a DDM] ficam com essa fantasia.
}

A falta de agilidade na resposta dos serviços também é vista como um fator inibidor da adesão da mulher à proposta do serviço de atenção psicossocial. O tempo demandado de tratamento é apontado como motivo de resistência das usuárias, pois estas buscariam uma resolução a curto prazo da sua situação. No entanto, a duração do processo psicoterápico pode ser longa, o que, muitas vezes, desmotiva as mulheres a persistirem no tratamento.

Os serviços que as entrevistadas mencionam como referências utilizadas são: DDMs, hospitais, centros de atendimento especializado no campo da saúde, e serviços de orientação jurídica, indicando serem as profissionais que mais dominam o conjunto do atendimento intersetorial. Dentro da atenção psicossocial, destaca-se um serviço da rede pública, a Casa Eliane de Grammont, que aglutina os demais, atuando como uma referência interna a essa modalidade de atendimento. 


\section{Assistência de orientações básicas}

A assistência de orientações básicas reúne serviços com vocação pluriprofissional e é caracterizada pelo predominante trabalho de orientação e educativo. A formação das entrevistadas em cada um dos serviços é bastante diversa: biblioteconomia, teologia, ciências sociais e serviço social.

A maioria das profissionais da assistência de orientações básicas possui forte envolvimento no movimento feminista e acredita na participação da mulher na solução de seus problemas. A emancipação e independência femininas são valores tidos como centrais na/e para a prática profissional das entrevistadas.

Falamos para ela: 'Tudo isso aconteceu porque você permite. Não existe uma ação solitária. Existem duas pessoas numa relação. Podemos te fortalecer para que você saiba que direção seguir e estar ajudando você a construir novas possibilidades. Mas quem vai dar a arrancada é só você. Tudo acontece só enquanto você deixar.

A satisfação de ver as mulheres crescendo, se modificando, tomando decisão, se fortalecendo é muito grande.

Ao contrário dos profissionais da assistência jurídica e psicossocial, as entrevistadas da assistência de orientações básicas percebem haver certa invisibilidade do tema VCM no cotidiano dos serviços em que trabalham. Comentam a respeito da dificuldade da mulher em expor o problema. São as únicas a constatarem essa dificuldade, que aliam ao fato de a maioria dos serviços não se dedicarem exclusiva ou diretamente ao atendimento de casos de VCM, mas lidarem com casos mais gerais de vulnerabilidade social. Alguns profissionais consideram, também, que não possuem competência técnica para a abordagem de casos de VCM.

\footnotetext{
A prioridade da casa não são os casos de violência, embora eles sejam atendidos.

Raramente chegam casos de mulheres que sofreram violência física. Gostaria de atender, mas só vou quando tiver um maior domínio da técnica de atendimento, maior vivência.

Existem muitos casos de violência, mas as mulheres não procuram os serviços por medo ou vergonha.
}

O ideal de gênero sustenta a percepção das entrevistadas sobre a VCM. Acreditam que o móvel das situações de violência está no desequilíbrio de poder entre homens e mulheres. A impossibilidade de negociação dialogada conduziria aos episódios de agressão.

O homem desempoderado, fragilizado, que reafirma seu poder através da violência. 
Essa relação de poder é tão natural para o homem que, quando as mulheres se libertam, eles vão e as matam.

A fala das mulheres e a escuta oferecida pelo serviço são vistas como pontos centrais do atendimento. Assim como na assistência psicossocial, a fala é valorizada como acesso à subjetividade da mulher e caminho para seu fortalecimento, sempre dentro da perspectiva feminista.

Conhecem serviços policiais, jurídicos, de atenção psicossocial e os de orientações básicas entre si, porém não necessariamente realizam encaminhamentos. Duas entrevistadas criticam as DDM, afirmando que as atitudes tomadas na instituição são pouco coerentes com a situação vivida pelas mulheres que a procuram. Uma delas diz que as delegacias deixam a desejar, chegando a debochar de algumas queixas. A outra, apesar da crítica à assistência policial, afirma ter como desejo que as mulheres consigam visualizar a violência como crime.

\section{Considerações finais}

A diferença entre as propostas e finalidades dos trabalhos representa uma barreira para o atendimento intersetorial e multiprofissional, nem sempre percebida de forma clara pelos profissionais. Apesar das diferenças entre os seus discursos, percebe-se, de um lado, um alinhamento entre assistência jurídica e policial e, de outro, assistência de orientações básicas e psicossocial. Internamente a estes dois grandes domínios assistenciais, as definições do problema e projetos de intervenção são similares, inclusive em termos de suas linguagens, demarcando dois grandes territórios relativamente afastados na assistência.

Os recortes de aproximação e adequação dirigidos às mulheres em situação de violência mostram-se bastante condicionados pela formação, trajetórias profissionais e, em alguns casos, engajamento político-ideológico dos entrevistados. Os profissionais da assistência jurídica e policial, bacharéis em Direito, tratam a violência com base na linguagem jurídicopolicial, cujo olhar para a mulher e sua situação de violência é redutor aos aspectos legais do caso. Nesse sentido, lidam mais com a violência (como crime) do que com a atenção à mulher.

Em contrapartida, os profissionais da assistência psicossocial não operam a mesma disjunção entre a violência e a mulher como objeto do seu trabalho. Lidam com a assistência a sujeitos em situação vulnerável, e, assim, seu objeto de intervenção é a subjetividade da mulher quanto às experiências vividas. Se esta visão é, em parte, própria ao escopo deste trabalho, parece ser reforçada, neste caso, devido à origem desses profissionais no movimento social. Além do atendimento à VCM constituir uma escolha profissional sua, fazem-no dentro de seu lidar, em geral, com situações de vulnerabilidade social.

$\mathrm{Na}$ assistência jurídico-policial, são profissionais de carreira que ocupam as posições no atendimento e, nem sempre, encontram-se dispostos a lidar profissionalmente com as especificidades do trabalho com VCM, assim como já havia observado Barsted (1994). 
Embora cada entrevistado aponte conhecer diferentes tipos de serviços, este conhecimento não se traduz sempre em articulação assistencial. Mesmo quando ocorrem encaminhamentos, permanece uma dificuldade de compreensão e comunicação quanto aos fluxos assistenciais e às propostas de intervenção. A assistência acaba fragmentada, já que a necessidade da mulher não é abordada em sua integralidade pelos serviços, dentro de um projeto conjunto. Mais ainda, parece haver certa desqualificação mútua, como é o caso dos profissionais da atenção psicossocial em relação às DDM, e vice-versa.

Outro aspecto a considerar é que, de forma geral, os serviços públicos ligados a estratégias inovadoras não consolidadas sentem-se muito dependentes das políticas de governo e mudanças de gestão. A trajetória dos serviços, os investimentos a ele direcionados, a integração de objetivos na rede ficam condicionados aos momentos políticos da gestão municipal, $e$ comprometem a qualidade e a constância dos atendimentos. Aqueles mais presos às rotinas e prescrições legais não sofrem muitas alterações ao sabor das mudanças políticas, com as trocas de governo, ao contrário daqueles originários de conjunturas muito específicas.

Essa instabilidade institucional atinge também as ONGs, ainda que por razões diversas, tais como a capacidade de auto-sustentação de cada qual. No caso jurídico e policial, tal instabilidade não se verifica em razão da própria dissolução do problema violência no interior da questão familiar mais geral, aspecto central do Direito e, portanto, mais independente das injunções político-conjunturais. Contudo, esse aspecto protetor da estabilidade institucional é enfraquecedor do problema violência diante das outras questões do Direito de Família.

A comunicação entre serviços públicos e organizações não governamentais e entre os serviços públicos entre si se dá, quase exclusivamente, pela via do encaminhamento individual de cada cliente. $\mathrm{O}$ percurso da mulher pelos diferentes serviços não é acompanhado e os fluxos assistenciais não são pensados em função dos casos.

Em síntese, racionalidades operacionais diversas e conflitantes convivem nesse conjunto de serviços, reforçando a inexistência de projeto comum $e$ obstaculizando eventuais interfaces e o compartilhamento de valores. Assim, o esforço de construção de uma rede teria de projetar-se em um duplo sentido. Um primeiro, o de ajustar definições e projetos, unificar campanhas e discussões e produzir a assistência em conjunto. Um segundo sentido seria o de construir a interação/ comunicação interinstitucional. Para ambos, há que se criar ativamente protocolos assistenciais e ferramentas tecnológicas compatíveis, pois, como enfatizam Schraiber et al. (1999, p.234), "um projeto de trabalho de base comunicativa não se inicia sem prever práticas e instrumentos para tal e quais informações serão alvo desses procedimentos". Nesse sentido, a integração entre os diversos setores da assistência especializada a mulheres em situação de violência depende da construção de tecnologias que permitam o ajuste dos projetos e das definições de objetivos. O papel do Estado, fomentando e apoiando tais construções, permanece fundamental. 


\section{Colaboradores}

As autoras participaram igualmente de todas as etapas de elaboração do artigo.

\section{Referências}

BARSTED, L.L. Violência contra a mulher e cidadania: uma avaliação das políticas públicas. Cad. CEPIA, V.1, p.9-25, 1994.

BRANDÃO, E.R. Violência conjugal e o recurso feminino à polícia. In: BRUSCHINI, C.; HOLLANDA, H.B. (Orgs.). Horizontes plurais: novos estudos de gênero no Brasil. São Paulo: Fundação Carlos Chagas, 1998. p.51-84.

CAMPOS, C.H. Justiça consensual e violência doméstica. Textos bem ditos. Porto Alegre: Themis, 2002.

CARRARA, S.; VIANNA, A.R.B.; ENNE, A.L. "Crimes de bagatela": violência contra a mulher na justiça do Rio de Janeiro. In: CORRÊA, M. (Org.). Gênero e cidadania. Campinas: Pagu/Núcleo de Estudos de Gênero, Unicamp, 2002. p.71-106.

D'OLIVEIRA, A.F.P.L. Violência de gênero, necessidades de saúde e uso de serviços em atenção primária. 2000. Tese (Doutorado) - Faculdade de Medicina, Universidade de São Paulo, São Paulo.

D'OLIVEIRA, A.F.P.L.; SCHRAIBER, L.B. Identificando possibilidades e limites para a redução da violência contra as mulheres em três capitais brasileiras. São Paulo: Departamento de Medicina Preventiva, Faculdade de Medicina, USP, 2005. Relatório de pesquisa.

EMIRBAYER, M.; GOODWIN, J. Network analysis, culture, and the problem of agency. Am. J. Sociol., V.99, n.6, p.1411-53, 1994.

FARAH, M.F.S. Gênero e políticas públicas. Estudos Feministas, v.12, n.1, p.47-71, 2004.

GARCIA-MORENO, C; JANSEN, H.A.M.F; ELLSBERG, M.; HEISE, L.; WATTS, C. WHO multi-country study on women: initial results on prevalence, health outcomes and women's responses. Genebra: WHO Press, 2005.

GUIA DE SERVIÇOS. Mulheres em situação de violência: guia prático de serviços: município de São Paulo, 2000. São Paulo: Coletivo Feminista Sexualidade e Saúde (CFSS)/Centro de Saúde Escola S. B. Pessoa, Departamento de Medicina Preventiva, Faculdade de Medicina, Universidade de São Paulo, 2000.

MASSUNO, E. Delegacia de Defesa da Mulher: uma resposta à violência de gênero. In: BLAY, E. (Org.). Igualdade de oportunidade para as mulheres. São Paulo: Humanitas/ FFLCH/USP, 2002. p.25-55.

MINAYO, M.C.; SOUZA, E.R. Violência e saúde como um campo interdisciplinar e de ação coletiva. Hist., Ciên. Saúde - Manguinhos, v. 4, n.3, p.513-31, 1997/1998.

PEDUZZI, M. Equipe multiprofissional de saúde: a interface entre trabalho e interação. 1998. Tese (Doutorado) - Faculdade de Ciências Médicas, Universidade Estadual de Campinas, Campinas.

PINTO, M.D.G. Cidadania e direitos reprodutivos. Advocacy em direitos reprodutivos e sexuais: workshops nacionais - além do Cairo de Beijing: fortalecendo as organizações de mulheres no Brasil. Brasília: Agende Ações em Gênero, Cidadania e Desenvolvimento, 1999.

SAFFIOTTI, H.I.B. Violência doméstica: questão de polícia e da sociedade. Gênero e Cidadania, Pagu/ Núcleo de Estudos de Gênero. Campinas: Unicamp, 2002. p.59-69. 
SCHRAIBER, L.B. Pesquisa qualitativa em saúde: reflexões metodológicas do relato oral e produção de narrativas em estudo sobre a profissão médica. Rev. Saúde Pública, v.29, n.1, p.63-74, 1995.

SCHRAIBER, L. Planejamento, gestão e avaliação em saúde: identificando problemas. Ciênc. Saúde Coletiva, v.4, n.2, p.221-42, 1999.

SCHRAIBER, L.B.; D’Oliveira, A.F.P.L. Violência contra a mulher: interfaces com a saúde. Interface Comunic., Saúde, Educ., v.3, n.5, p.11-28, 1999.

KISS, L.B.; SCHRAIBER, L.B.; D'OLIVEIRA, A.F.P.L. Posibilidades de una red intersección para atendimiento a mujeres en situación de víctimas de violencia. Interface - Comunic., Saúde, Educ., v.11, n.23, p.485-501, set/dez 2007.

El artículo discute datos obtenidos en entrevistas semi-estructuradas con 29 informantes de un conjunto de servicios de asistencia a casos de violencia doméstica contra mujeres. Se investigó el modo como los profesionales perciben sus trabajos y cuál es el grado de integración de las acciones entre ellos, a fin de caracterizarlos o no como una red con vistas a la inserción de los servicios básicos de la salud aún no participantes a la época. Se concluye que racionalidades operacionales diversas y conflictantes conviven en este conjunto, cercenando su integración efectiva. La inexistencia de un proyecto común refleja la dificultad de composición entre saberes y programas de atención con lógicas muy distintas, sin interfaces comunes y valoración mutua. Comprendiendo diversos sectores de asistencia a la población en el país, la integración depende de la construcción de canales de comunicación y formas tecnológicas de asistencia que permitan el ajuste de proyectos y definiciones a los objetivos compartidos.

PALABRAS CLAVE: Violencia contra la mujer. Género. Redes. Intersectorialidad. Salud de la mujer. 


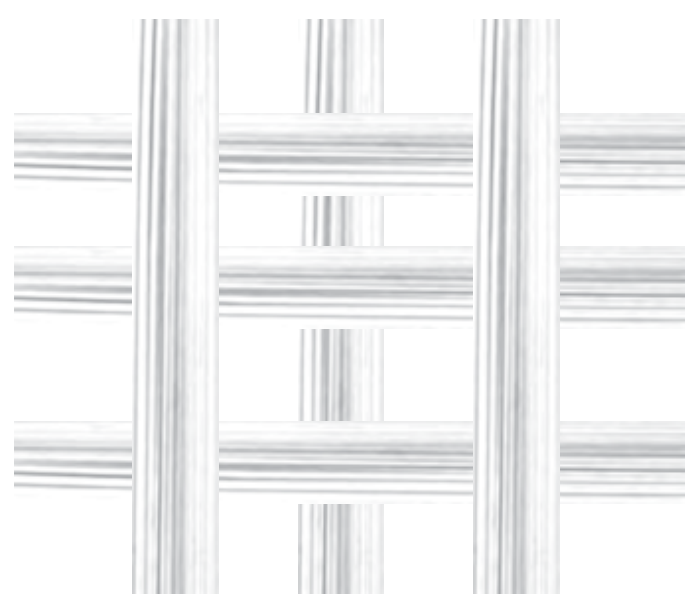

